\title{
BMJ Open Worldwide variation in human growth and the World Health Organization growth standards: a systematic review
}

\author{
Valerie Natale, Anuradha Rajagopalan
}

To cite: Natale $V$,

Rajagopalan A. Worldwide variation in human growth and the World Health Organization growth standards: a systematic review. BMJ Open 2014;4: e003735. doi:10.1136/ bmjopen-2013-003735

- Prepublication history and additional material for this paper is available online. To view these files please visit the journal online (http://dx.doi.org/10.1136/ bmjopen-2013-003735).

Received 5 August 2013 Revised 31 October 2013 Accepted 18 November 2013

CrossMark

The Forgotten Diseases Research Foundation, Santa Clara, California, USA

Correspondence to Dr Valerie Natale; vnatale@forgottendiseases.org

\begin{abstract}
Objective: The World Health Organization (WHO) has established a set of growth curves for use as international standards in children up to age 5 . The WHO's position is that all economically advantaged children who were breastfed as infants grow similarly. As a result, a single set of growth charts can be used to judge growth in any child, regardless of race or ethnicity. The goal of this study was to compare mean heights, weights and head circumferences from a variety of studies with the WHO's data.

Design: We compared data from the WHO's Multicentre Growth Reference Study (MGRS) with data from studies performed in 55 countries or ethnic groups.
\end{abstract}

Data sources: PubMed, WHO Global Database on Child Growth and Malnutrition, SciELO, Google Scholar, Textbooks and Ministries of Statistics and Public Health. Eligibility criteria: Large recent studies (1988-2013) of economically advantaged groups, including comparisons with cohorts of breastfed children wherever possible.

Results: Height varied somewhat among different national and ethnic groups. Means were generally within 0.5 of an SD of the MGRS means. Weight varied more than height, but the low MGRS means were seen as endorsing slenderness in the midst of an obesity epidemic. The mean head circumference varied widely. In many groups, means were consistently $0.5-1$ SD above the MGRS mean. Head size in breastfed children at any age examined was far closer to local norms than to the MGRS means.

Conclusions: Height and weight curves may not be optimal fits in all cases. The differences between national or ethnic group head circumference means were large enough that using the WHO charts would put many children at risk for misdiagnosis of macrocephaly or microcephaly. Our findings indicate that the use of a single international standard for head circumference is not justified.

Systematic Review Registration: PROSPERO (\# CRD42013003675).

\section{INTRODUCTION}

The importance of growth monitoring in paediatric care is well recognised. Unduly slow

\section{Strengths and limitations of this study}

- We found data from 55 different countries or ethnic groups (over 11 million children), making this study a large-scale comparison of growth in healthy children around the world.

- We found a relatively few studies from South America and sub-Saharan Africa. This limitation was due to the relatively few studies meeting our inclusion criteria in these areas.

- We also found extensive data comparing growth in breast- and formula-fed infants. This data facilitated comparisons with the MGRS data.

or rapid growth can indicate serious medical conditions, including genetic disorders, chronic disease, infectious disease, abuse or neglect and a variety of other problems.

Although analysis of information about an individual's growth can be complex, clinicians often look for patterns that may indicate abnormal growth. Examples include data points for a child that cross centile lines on a growth curve quickly, or values $>2$ SDs from the mean (below the 2.3rd and above the 97.7th centiles). Head circumference values below the $2.3 \mathrm{rd}$ centile may indicate poor brain growth, and height values in this range are often used to define short stature. Insurance companies and national healthcare systems often use SD cut-offs as criteria for coverage of growth hormone therapy. Thus, it is critically important that clinicians use curves with centiles that accurately reflect a child's expected pattern of growth.

The WHO's position is that unconstrained growth of economically advantaged breastfed infants and children does not vary substantially, and that a single set of growth curves can describe a human physiological norm up to age 5. ${ }^{2}$ Accordingly, the WHO calculated a set of normative curves from the Multicentre Growth Reference Study $\left(\right.$ MGRS $\left.^{13}\right)$. Study participants came from single cities in six countries (Brazil, Ghana, India, Norway, Oman and the USA). 
The WHO refers to its curves as growth standards, or tools that provide a norm or desirable target, involve a value judgement, and describe how children 'should grow' in all countries. ${ }^{3-8}$ Standards are different from references, which show how children are actually growing in a given place and time. The WHO notes that any deviations from its standards should be considered as evidence of 'abnormal growth'. ${ }^{3}$ To date, $>100$ countries have adopted the MGRS curves. ${ }^{9}$

Many recent studies have found growth patterns of economically advantaged children that differ from the MGRS means. These studies were rigorous. Unfortunately, however, they focus on no more than two countries or ethnic groups, ${ }^{10-16}$ do not compare their data with the MGRS data, were published before the MGRS curves ${ }^{11} 14{ }^{17-20}$ or are written in local languages. ${ }^{21-23}$ To date, no one has carried out a large-scale comparison of data from the MGRS and different studies. As a result, the magnitude of international differences in growth is not fully evident.

In addition, the WHO has not published data supporting the idea that head circumference does not vary between nations and ethnic groups, nor has it published site-specific data for weight and head circumference from the MGRS study. Owing to the large number of countries using the WHO curves and because errors in diagnosis can occur when using growth curves with inaccurate centiles, we decided to compare the MGRS data with data from growth studies performed in different countries.

We analysed studies from 55 countries or ethnic groups, including 3 that had participated in the MGRS (India, Norway and the USA). We compared height, weight and head circumference from birth to age 5 , and strove to use data from breastfed economically advantaged children. Like the WHO, ${ }^{25}$ we defined 0.5 of an $\mathrm{SD}$ as a benchmark for significant differences between groups (called outlying groups or outliers here).

\section{METHODS}

The protocol for this study is registered with PROSPERO (\# CRD42013003675).

\section{Literature search}

We searched PubMed, the WHO Global Database on Child Growth and Malnutrition, SciELO, Google Scholar and Google between May 2012 and May 2013. A final search was also performed immediately prior to publication. Our search terms were ["head circumference" OR birthweight OR weight OR length OR height OR anthropometric OR anthropometry OR "occipitofrontal" OR "growth curves" OR "length or height or stature" OR "growth charts"] alone or AND [ethnic group or nation]. Searches were performed in English, Arabic, Chinese, Czech, Dutch, French, German, Japanese, Icelandic, Italian, Korean, Norwegian, Polish, Portuguese, Russian, Spanish and Turkish. Most of the
non-English papers had English abstracts. Google Translate and colleagues with knowledge of other languages aided in translation.

We scanned publication references and 'cited by' papers in Google Scholar, and contacted researchers to request information or sample size data not included in publications. Our initial screen identified $\sim 2500$ publications; $\sim 900$ that appeared to be relevant were selected for close review. 'Relevance' was defined as publications that, according to their abstracts, focused on growth, including the creation of curves and/or mean or centile values at specific ages. These included papers, books, one $\mathrm{PhD}$ thesis and government-made national growth curves. We reviewed these leads and determined which studies met our inclusion/exclusion criteria (see below and online supplementary figure S1). Differences of opinion were discussed until agreement was reached.

\section{Study selection and data extraction}

The MGRS study enrolled economically advantaged children who had been breastfed as infants. ${ }^{13}$ We strove to find studies duplicating these conditions. The MGRS assumed that children at study sites in two developed nations (Norway and the USA) were unconstrained by economic hardship. We made this assumption for nations scoring $\geq 0.750$ on the United Nations Human Development Index (HDI) at the time a study was performed. This approach helped us to reduce bias from growth data from children who were malnourished or afflicted with poverty-related medical conditions that affect growth. Other studies specifically cited favourable circumstances as inclusion criteria. ${ }^{19-21}$ 24-26

Study quality was improved by the use of peer-reviewed publications and data from national health surveys. Online supplementary table S1 has a column ranking each study by its relative risk for the biases noted above. Rankings were described on the following scale: low, lowmedium, medium, medium-high and high. We used studies with rankings of low and low-medium. A study was scored low-medium if it met the conditions noted above but some uncertainties existed. An example would be the absence of a statement in a high HDI country about excluding children with diseases affecting growth. As another example, the MGRS study was scored lowmedium because of potential attrition bias. ${ }^{27}$

For size at birth, we used studies reporting measurements by gestational age when possible. ${ }^{10} 222^{24} 28-51 \mathrm{In}$ addition, two studies defined 'term birth' in this way. ${ }^{52} 53$ This approach allowed us to duplicate the MGRS's 37-41 completed weeks 'term birth.' Some studies defined term birth as $37-42$ weeks. ${ }^{12}$ 54-59 A study from Sweden defined term birth as 37-43 gestational weeks. ${ }^{60}$ Another study of birth size in Sweden noted deceleration of growth after 40 weeks $^{61}$; thus, the studies including data from gestational ages after 41 weeks (in Sweden at least) are unlikely to skew the data significantly. The Euro-12 used data from 37-44 weeks. ${ }^{62}$ Five studies noted 'term birth'. ${ }^{2325} 26$ 63-68 Our 
remaining birth studies simply reported size at birth. $^{14} 21$ 69-76

Means at the following ages were analysed: birth, 6 months (head circumference only), and 12, 18, 24, 36, 48 and 60 months. Data were transferred to Excel spreadsheets and checked and rechecked by both authors.

\section{Calculation of weighted averages and composite SDs}

We calculated weighted averages $\left(\overline{\mathrm{X}_{\mathrm{t}}}\right)$ and composite SDs $\left(\sigma_{t}\right)$ for data at birth using standard methods. Composite SDs were calculated as follows:

$$
\sigma_{\mathrm{t}}=\sqrt{\left\{\sum_{\mathrm{i}=1}^{\mathrm{k}}\left(\mathrm{n}_{\mathrm{i}}-1\right) \mathrm{V}_{\mathrm{i}}+\sum_{\mathrm{i}=1}^{\mathrm{k}} \mathrm{n}_{\mathrm{i}}\left(\overline{\mathrm{X}}_{\mathrm{i}}-\overline{\mathrm{X}}_{\mathrm{t}}\right)^{2}\right\} /\left(\mathrm{n}_{\mathrm{t}}-1\right)}
$$

In this calculation, $\mathrm{k}$ is the number of term gestational age groups in each study (1 group/week; 37-41 weeks), $n_{i}$ the sample size of each gestational age group, $n_{t}$ the total number of samples in each ethnic group, $\left(n_{t}-1\right)$ the degrees of freedom, $\mathrm{X}_{\mathrm{i}}$ the mean value in each gestational age group and $\mathrm{V}_{\mathrm{i}}$ the variance in each gestational age group. The first sum inside the root sign is the overall error sum of squares; the second sum is the group sum of squares. When added together and divided by the degrees of freedom, the result is variance. The square root of variance is $\mathrm{SD}$, which we used to calculate SEs.

\section{Defining significant differences}

The WHO used $0.5 \mathrm{SD}$ as a benchmark for clinically significant differences. ${ }^{25}$ We adopted this cut-off. However, $0.5 \mathrm{SD}$ is normally considered to be of moderate clinical significance and $<0.5$ SD may not be an optimal definition for not significantly different. Consequently, we also identified differences that were smaller but consistent. This was defined as a mean that was 0.25-0.49 SD from the MGRS mean in at least four of the ages noted above. Note that $0.25 \mathrm{SD}$ outliers measure studies as a whole: if means at $\geq 4$ ages were $\geq 0.25$ SD from the MGRS mean, the country was identified as a $0.25 \mathrm{SD}$ outlier.

\section{RESULTS}

\section{Study selection}

This review uses studies from the following countries/ ethnic groups: Argentina, ${ }^{44}$ Australia (indigenous and non-indigenous), ${ }^{28} 49{ }^{75}$ Belgium, ${ }^{59}$ Brazil, ${ }^{41}$ Canada (indigenous and non-indigenous), ${ }^{10}{ }^{48} 77$ China, ${ }^{65} 71$ Czech Republic, ${ }^{73}$ Denmark, ${ }^{16}{ }^{52}{ }^{66}{ }^{2}$ Eypt, ${ }^{19}$ Euro-12, ${ }^{62}$ Finland, ${ }^{37}{ }^{64}$ France, ${ }^{29} 78$ Germany $^{13}{ }^{50}{ }^{79}$ Greece, ${ }^{57} 80$ Hong Kong, ${ }^{30}$ Iceland, ${ }^{53} 81$ India (birth and postnatal $^{20} 33 \quad 388^{83}$ ), Iran, ${ }^{55}$ Ireland, ${ }^{84}$ Israel, ${ }^{34}$ Italy, ${ }^{31} 85$ Japan, ${ }^{14} 3956$ Kuwait, ${ }^{43}$ Lebanon, ${ }^{36}$ Libya $^{86}$ Malaysia, ${ }^{35}$ Mexico, ${ }^{45}$ Moroccans (in the Netherlands and Spain), ${ }^{22}{ }^{87}$ Nepal, $^{63}$ the Netherlands (including Moroccans and Turks), ${ }^{18}{ }^{87-90}$ New Zealand (indigenous and non-indigenous), ${ }^{58} \quad{ }^{91-93}$ Nigeria $\left(\right.$ birth $\left.^{26}\right)$,
Norway, ${ }^{12} 5167$ Poland, ${ }^{94}{ }^{95}$ Portugal,${ }^{46}$ Russia, ${ }^{72}$ Saudi Arabia, ${ }^{25}$ Scotland, ${ }^{47}$ Singapore, ${ }^{40}{ }^{69}$ South Korea, ${ }^{70} 74$ Spain (birth; Caucasians, Moroccans, South Americans and sub-Saharan Africans born in Spain), ${ }^{22}$ Spain (postnatal) ${ }^{96}$ Sweden, ${ }^{60}$ Switzerland, ${ }^{23}$ Taiwan, ${ }^{42}$ Turkey, ${ }^{21}{ }^{90}$ United Arab Emirates, ${ }^{24}$ the $\mathrm{UK}^{54}$ and the USA, ${ }^{32} 97$ plus the MGRS. ${ }^{13}$ The participants in these studies totalled roughly 11 million children (see online supplementary table S1).

\section{Height}

A publication authored by the MGRS showed that height means within the MGRS study sites did not vary significantly from birth to age $5 .^{2}$ In general, most means we analysed also fit within $\pm 0.5 \mathrm{SD}$ of the MGRS means (results not shown). Groups with outlying means at three or more ages included Pacific Islanders,${ }^{58}$ the Netherlands, ${ }^{18}$ Finland, ${ }^{98}$ India $^{20}$ and Saudi Arabia. ${ }^{25}$ Europeans and Pacific Islanders were above the $+0.5 \mathrm{SD}$ mark; other groups were below $-0.5 \mathrm{SD}$.

Pacific Islander adults are not taller than other groups $^{99}$; it is likely that increased height in these children is due to prematurely accelerated growth caused by increased weight (E. Rush, personal communication). ${ }^{100}$ As a result, we were concerned about high weight and high body mass index (BMI). We investigated this possibility by using the Centers for Disease Control and Prevention's (CDC's) paediatric BMI calculator ${ }^{\mathrm{i}}$ to determine BMIs for Pacific Islander children aged 2-5 with weights and heights at the 50th centiles; all values came from a large recent study of this group. ${ }^{92}$ The values we obtained were between the 87th and 98th centiles, with the majority $>90$. The CDC cutoff centile for overweight is the 85th centile. Thus, an average-sized child in that study would be overweight at a minimum, even when accounting for differences in body composition. ${ }^{99}$ Alternatively, the same calculations for Dutch children ranged from the 39 th to the 56th centiles, with the majority $<50$. These findings imply that increased linear growth in the Dutch population is not due to excess weight.

Infants in some nations were also longer than the MGRS means. For example, the average length of all children in Iceland was $\sim 2 / 3$ of an SD longer than the MGRS charts at birth and 12 months in a study that measured children at these two time points. ${ }^{53}$ Male and female infants in Denmark were also outliers up to age $1{ }^{66}$ The Icelandic study was small, but the Danish study was a large national survey. In addition, Moroccan infants in the Netherlands were outliers at age $1 .^{87}$ Finally, a large German study found that means for German girls and boys up to age 5 were at the 62 nd and 60th MGRS centiles, respectively. ${ }^{101}$ The authors deemed these differences to be sufficient to warrant the use of national growth curves over the MGRS curves. ${ }^{101}$ Overall, $20 \%$ of the total means were $\geq 0.5$ SD from the

${ }^{\mathrm{i}}$ http://apps.nccd.cdc.gov/dnpabmi/Calculator.aspx?

CalculatorType $=$ Metric 
MGRS mean. However, the percentage of means at least $\pm 0.25 \mathrm{SD}$ from the corresponding MGRS means at 4 or more time points was $44 \%$ for boys and $48 \%$ for girls.

\section{Breastfed infants and children}

Several studies have examined the effects of breastfeeding on linear growth. Although breastfed cohorts may be smaller than formula-fed cohorts, ${ }^{52} 56$ in most studies we analysed, the lengths of breastfed infants and children were closer to local references than to the WHO standards $^{12} 1656102103$ or, in pre-MGRS studies, the mean lengths of breast- and formula-fed infants were not significantly different. ${ }^{104}{ }^{105}$ We excluded older studies (before 1988) comparing breastfed and formula-fed infants due to changes in formula content with time. A Japanese breastfed cohort was at least $0.5 \mathrm{SD}$ below the MGRS mean at every age measured; means for formula-fed children were either within $0.25 \mathrm{SD}$ of the MGRS mean or not below $0.5 \mathrm{SD}^{56}$ No pattern was found when comparing Greek breastfed infants with the national standards and MGRS data. ${ }^{57} 80$

\section{Weight}

We compared mean MGRS weight-for-age values with values from 24 to 54 (depending on age) countries or ethnic groups. The MGRS means were always at the low end of the range of values we obtained. Figure 1 is an example showing weight in boys and girls at age 24 months.

Overall, weight varied more than height. The percentage of outlying means in our analysis ranged $12-57 \%$, with a peak at $30-39 \%$. The greatest variation occurred

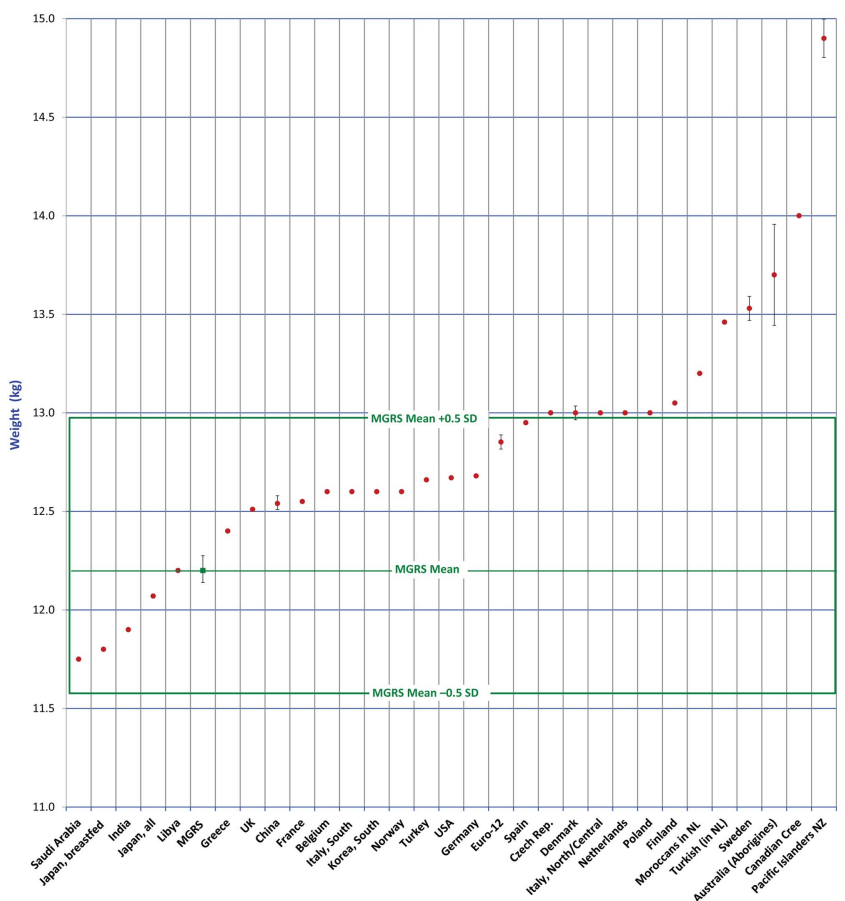

at the age of 12 months (60\% of means were outliers among boys and $44 \%$ for girls).

Importantly, $\sim 84 \%$ of outlying mean weights were above the MGRS +0.5 SD mark. Owing to the global obesity epidemic, the low position of the MGRS means in our range can be seen as endorsing the idea that slenderness is healthy. This is a strength of the MGRS curves, particularly since overweight and obesity pose significant health risks. However, clinicians working with children from groups that are somewhat taller or shorter than average should bear differences in mind when assessing weight centiles with the MGRS charts. This is particularly important when making determinations about failure to thrive (FTT).

Online supplementary figure S2 compares birth weight in boys and girls in 54 studies and the MGRS. Although the MGRS values were closer to the middle of the range of values at birth, outliers occurred above and below the mean, with highly developed nations well above the mean (Iceland) and well below it (Japan). Thus, the charts may not be good global fits for birth weight. A study in the UK came to this conclusion for British children. ${ }^{106}$

Overall, $31 \%$ of all weight means were at least $0.5 \mathrm{SD}$ from the WHO mean at any age, with $62 \%$ (boys and girls) of studies being $0.25 \mathrm{SD}$ outliers as defined above. Alternatively, results for a similar comparison of Euro- $12^{62}$ weight means and national European weight means identified only four $0.5 \mathrm{SD}$ outliers among 144 data points and $2 / 15$ (13\%; boys and girls) as consistent 0.25 SD outliers. We did not make this comparison for height because the Euro-12 study measured only length, and most other studies measured standing height at ages 2 and 3 .

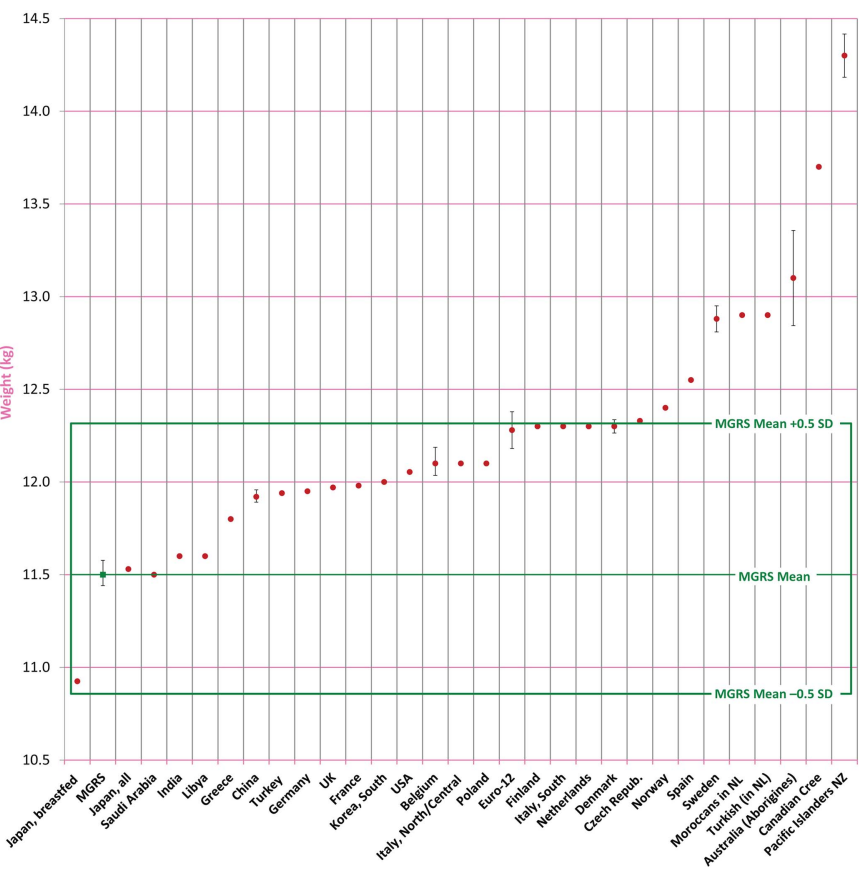

Figure 1 Weight at 2 years: 30 countries versus Multicentre Growth Reference Study (MGRS). The green box delimits the area within $0.5 \mathrm{SD}$ of the MGRS mean. The green line within the box shows the MGRS mean. (A) Boys; MGRS mean: $12.2 \mathrm{~kg}$; SD up: $1.55 \mathrm{~kg}$, down: $1.25 \mathrm{~kg}$. (B) Girls; MGRS mean: $11.5 \mathrm{~kg}$; SD up: $1.65 \mathrm{~kg}$, down: $1.25 \mathrm{~kg}$. Error bars show 1 SE. 
Breastfed infants and children

Weight differences between breast- and formula-fed cohorts were more substantial than for length/height. However, national breastfed means were not necessarily the same as the WHO means, and no overall pattern was found. For example, weights in Belgium and Norway were closer to the MGRS means at some ages and to local formula-fed means at other ages. ${ }^{12} 107$ Alternatively, a study in the USA found consistent differences between the two cohorts. ${ }^{102}$ Weights of Danish infants fed according to the WHO recommendations fluctuated but were generally $<0.25 \mathrm{SD}$ from the overall mean of breastfed and formula-fed infants combined. ${ }^{52}$ Mean cohort weights did not differ significantly in another Danish study, but were above the MGRS means. ${ }^{16}$ This finding mirrors that of a study in Sweden, which found no differences between the two feeding groups. ${ }^{104}$ Most breastfed Japanese infants up to age 2 were 0.5 SD outliers. ${ }^{56}$ All were lighter than formula-fed infants, who were not generally $0.5 \mathrm{SD}$ outliers.

\section{Head circumference}

Overall, head circumference varied far more than weight or height. Again, the MGRS mean values were at the low end of the range of values we found. Most outlying groups were European (including Turks), but Asian Indians, Australian aborigines, Canadian Cree, Japanese children at birth and Pacific Islanders were also represented. Figure 2 compares head circumference at age 24 months in 26 studies with the MGRS means. Eighteen means in each group were $0.5 \mathrm{SD}$ outliers. Figure 3 shows

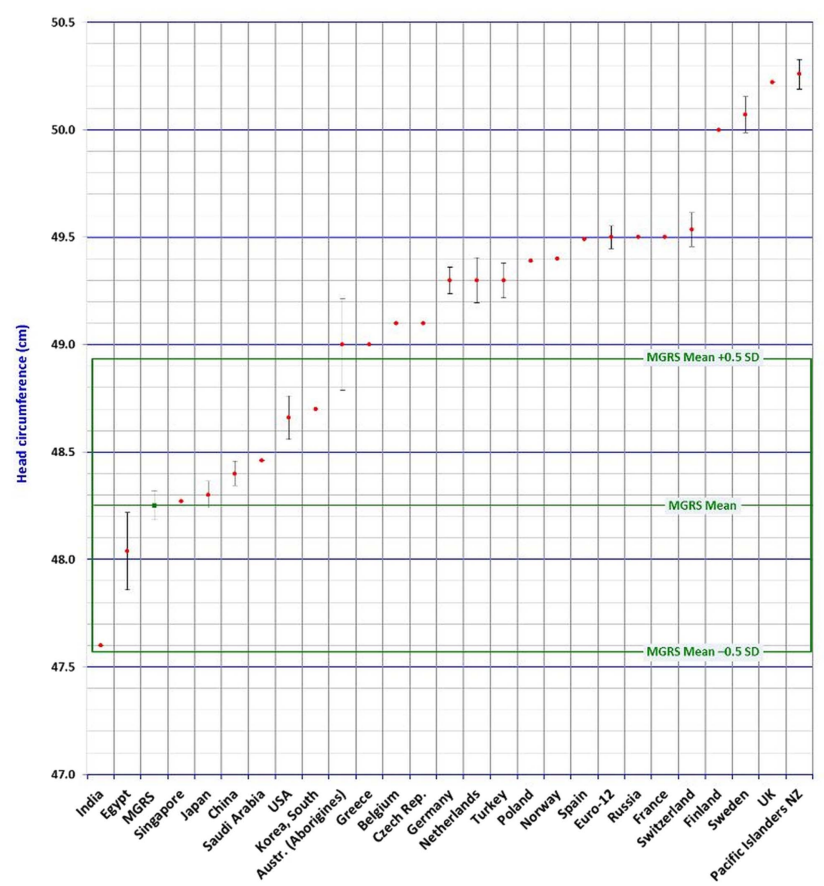

the percentage of outlying means at each age we analysed. Outliers ranged from $32-72 \%$ of age groups from birth to age 5. Overall, 219 means of 408 total were outliers $(54 \%)$. Of these, $202(98 \%)$ were above the $+0.5 \mathrm{SD}$ cut-off.

A total of $51 \%$ of female means and $56 \%$ of male means were $0.5 \mathrm{SD}$ outliers, and $69 \%$ of studies on boys and $78 \%$ of studies on girls were 0.25 SD outliers. The difference between the highest and the lowest mean values was $\geq 1.5$ MGRS SDs in the majority of ages.

Means in geographically proximal countries were closer. Figure 4 compares Euro-12 means at 24 months with European national means. ${ }^{62}$ There were no 0.5 outliers. In addition, there were only eight $0.5 \mathrm{SD}$ outliers of 182 data points from birth to 36 months (data not shown). Six of these points were from the UK. However, $31 \%$ of female study means from 0 to 5 and $44 \%$ of male studies were surpassed the 0.25 SD cut-off.

Data for Cree head size were included even though many Cree live in disadvantaged circumstances with a high prevalence of diabetes. Our reasons for using the data were that (1) diabetes (including gestational diabetes) apparently does not affect head circumference ${ }^{108}$ and (2) different studies have found large head sizes in the Cree, ${ }^{77} 109$ with their larger overall sizes dating back to a time when they maintained traditional lifestyles. ${ }^{110}$

In practical terms, these findings indicate that many children from groups analysed here would be extreme outliers above the 97.7 th centile/2nd SD above the mean on the MGRS's curves, and few would be extreme outliers below the 2.3rd centile/2nd SD below the mean. We

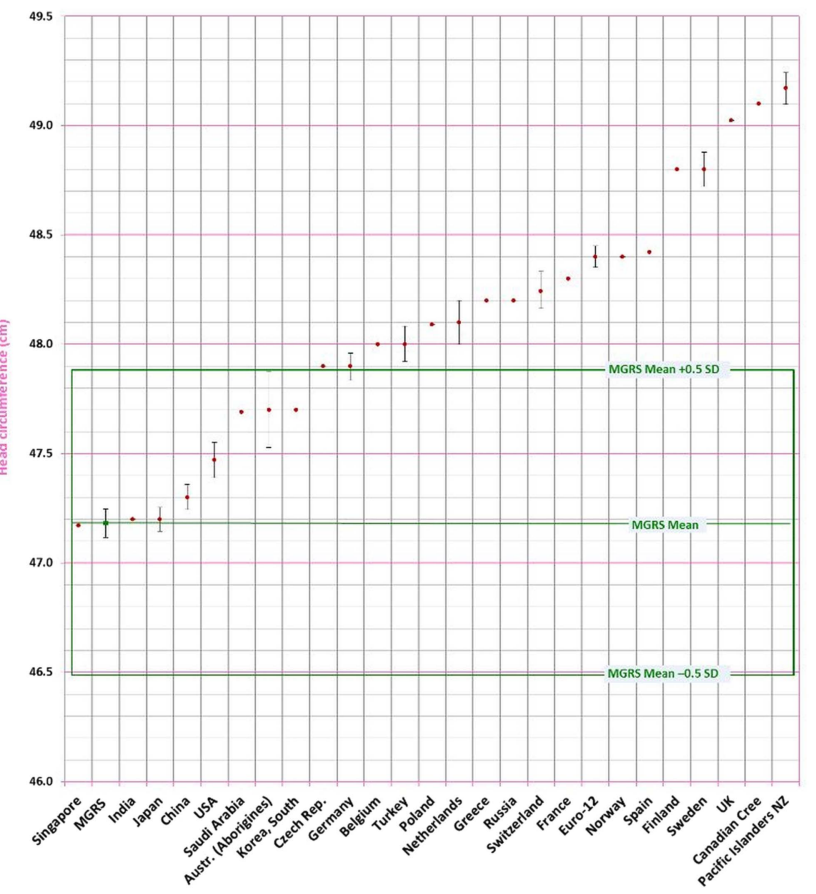

Figure 2 Head circumference at 2 years: 26 countries versus Multicentre Growth Reference Study (MGRS). The green box delimits the area within 0.5 SD of the MGRS mean. The green line within the box shows the MGRS mean. (A) Boys; MGRS mean: $48.25 \mathrm{~cm}$; SD: $1.36 \mathrm{~cm}$. (B) Girls; MGRS mean: $47.2 \mathrm{~cm}$; SD: $1.40 \mathrm{~cm}$. Error bars show $1 \mathrm{SE}$. 


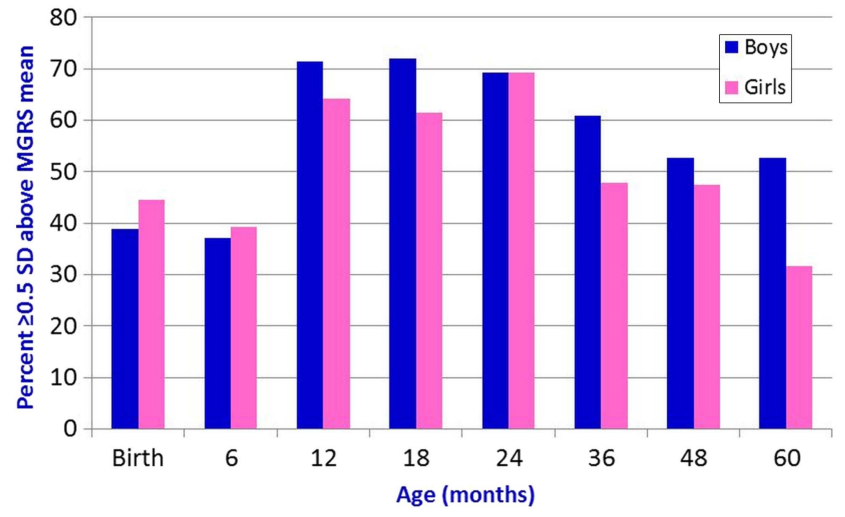

Figure 3 Percentage of head circumference outliers by age and sex. The figure shows the percentage of studies with head circumference means that were at least $0.5 \mathrm{SD}$ above or below the Multicentre Growth Reference Study (MGRS) mean. Half or more of all means for boys were beyond 0.5 SD at 12 months and older; at least $40 \%$ of means for girls were in this category in 6 of 8 age groups.

addressed this question by estimating the percentage of children from different national or ethnic groups who would be extreme outliers on the MGRS curves.

To do this, we determined MGRS values that were \pm 2 SDs from the MGRS mean for different ages and sexes. For example, the MGRS +2 SD value for 24-month-old boys is $51 \mathrm{~cm}$. Next, we determined centiles for these values in other groups. Thus, $51 \mathrm{~cm}$ is roughly the 73rd centile for British boys at the same age, meaning that $\sim 27 \%$ of British boys would be above the 97.7 th centile on the MGRS growth curves. Alternatively, $51 \mathrm{~cm}$ is approximately the 86th centile in the Euro-12 data, meaning that $\sim 14 \%$ of European 2-year-old boys overall would be above the MGRS's 97.7th centile. This estimate fits well with the fact that the Euro-12 male mean at 24 months is $\sim 0.9 \mathrm{SD}$ above the MGRS mean. Alternatively, only $0.02 \%$ of British boys and $0.26 \%$ of Euro- 12 boys would be below the 2.3rd centile on the MGRS charts. Note that the SD values for the MGRS, UK and Euro-12 studies were generally very close at all ages, especially for males, facilitating this comparison. This similarity was not the case for every country tested, and growth variation within individual nations presumably contributes to differences at the extremes when measured against the MGRS curves. Figure 5 shows percentages of extreme outliers for countries on different continents. Online supplementary figures S3 and S4 show extreme outliers for height and weight at age 2.

Euro-12 used 'strictly standardised methods of measurement' that mirrored the MGRS's, ${ }^{111}$ including use of a metal measuring tape applied firmly. ${ }^{112}$ Given the methodological similarities between both studies, it is unlikely that the large differences in means between the MGRS and Euro-12 studies are due to technique.

\section{Breastfed infants and children}

Head circumference means in breastfed infants and children were generally closer to local norms than to the
MGRS standards ${ }^{12} 107$ or close to formula-fed groups in pre-MGRS studies. ${ }^{52} 62102105$ A Turkish study found fluctuations in differences between the groups, but only measured infants until the age of 6 months. ${ }^{113}$ Head size in Japanese breastfed and formula-fed cohorts did not generally differ significantly at the ages tested (birth to 24 months), while differences from the MGRS means fluctuated. ${ }^{56}$ A Danish study found that head circumference in breastfed infants did not differ from nonbreastfed infants, and both groups had larger mean head sizes than the MGRS means. ${ }^{16}$

\section{DISCUSSION}

This study is a large international comparison of height, weight and head circumference means in children up to age 5. In order to minimise effects due to secular changes in growth, we used recent growth studies published within the same general time as the MGRS study. Overall and with some exceptions as noted, mean values for linear growth examined here were within $0.5 \mathrm{SD}$ from the MGRS means, although close to half of means were not consistent within 0.25-0.49 SD of the MGRS means. Among 0.5 SD outliers, Europeans were generally above $0.5 \mathrm{SD}$ and some other groups (eg, Saudi Arabians and Asian Indians) were below -0.5 SD. Thus, the curves may underindicate short stature in slightly taller European populations and overindicate it in shorter ones. Clinicians should keep this fact in mind when dealing with children from these populations.

Obviously, means for groups with small average body sizes, such as the Aka, Efé and Mbuti tribes, and others, would not fit into the MGRS charts and these groups would presumably require their own charts for optimal analysis of growth. Owing to the challenges of making charts for these populations (a relatively small population size, relative isolation, etc), their situations pose unique difficulties in this regard.

Variation in weight was greater, with $57 \%$ of male means and $39 \%$ of female means being outliers at 12 months. This large percentage may have been partially due to differences in feeding methods, but without specific studies, there is no way to know. Additionally, many of the higher weights in European populations may also have been partially due to their mildly greater lengths/heights.

The MGRS weight means tended to be at the low or very low end of the range of weights we found, and $84 \%$ of outlying weight means were above the MGRS mean. The position of the MGRS means can be seen as endorsement of slenderness and is therefore a strength of the MGRS curves. However, weight centile values must still be interpreted carefully in populations that are tall or short.

In addition, $16 \%$ of the outlying mean weights identified here were below the MGRS mean. Most were from India and Saudi Arabia. As noted, Indian children tended to be short and would therefore be expected to 

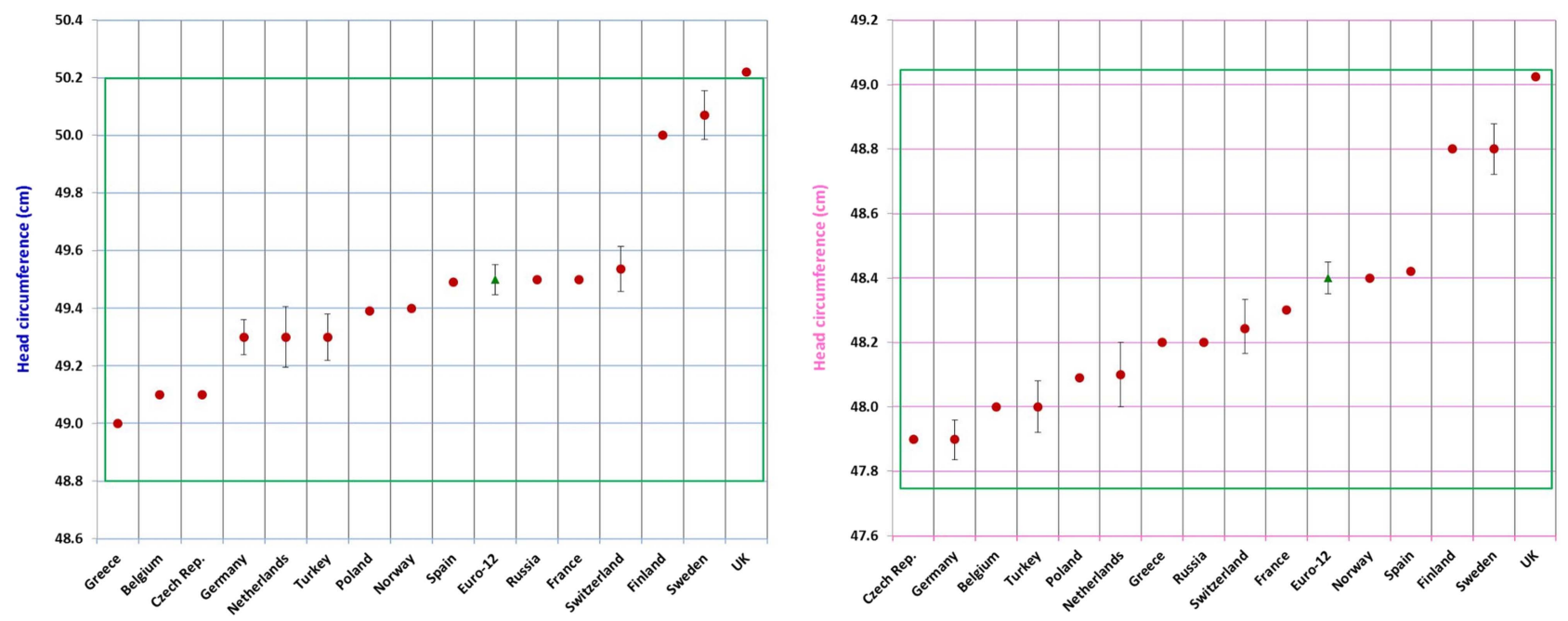

Figure 4 Euro-12 versus 15 European studies (head circumference, 24 months). (A) Boys; Euro-12 mean: $49.5 \mathrm{~cm}$; SD: $1.4 \mathrm{~cm}$. (B) Girls; Euro-12 mean: $48.4 \mathrm{~cm}$; SD: $1.3 \mathrm{~cm}$. Error bars show $1 \mathrm{SE}$. MGRS, Multicentre Growth Reference Study.

have lower weights; Saudi children were also at the low end of our height ranges.

In contrast, head circumference varied considerably. Variation between the extremes in each age/sex group was as high as 2.5 SDs. However, as noted in the text and shown in figure 4, variation was less in geographically proximate Europeans. This was also the case for eastern Asian populations analysed here (China, Japan and Singapore). Overall, means for these groups clustered together at all ages examined.

Although the WHO examined weight and linear growth in breast- and formula-fed infants prior to beginning the MGRS, head circumference was not examined. ${ }^{114-117}$ In addition, the final MGRS study did not publish site-specific head circumference data, apart from a small set of sex-pooled birth data. ${ }^{118}$ We found $0.5 \mathrm{SD}$ outliers in that data (Norway and Oman; not shown).

Also, studies comparing head size in breastfed and bottlefed children have found either no or modest size differences between them or found that head circumference in breastfed infants is closer to other local infants than it is to the WHO charts. ${ }^{12} 52102107119$ The Euro-12 study found that all size differences between breastfed and non-breastfed European children, including head size, were clinically irrelevant after the first birthday. ${ }^{105}$ Taken as a whole, these findings indicate that the MGRS head circumference curves are of questionable validity for global use.

The variation found here highlights the fact that growth and growth monitoring are complex processes. Growth is affected by genes, physiology, general health, general environment, nutritional status and other factors. Growth monitoring is affected by secular changes in size, the size of each study sample and its composition, measurement errors and other things.

Just as importantly, size at any age is affected by innate differences in anatomy. As an example, the craniums in
Polynesians are shaped differently when viewed from above and behind in comparison with those of other humans, and their cranial vaults are higher and larger. ${ }^{120}$ There are also differences between Chinese and Caucasian head morphology. ${ }^{121}$ Finally, the highly regarded works of William White Howells describe ethnic differences in skulls that are used to aid in the identification of human remains. $^{122} 123$ One of his works describes centuries-old Polynesian skulls as 'large'. ${ }^{122}$ Many or most of the differences he described may affect head circumference.

The WHO is correct to be concerned that the potentially smaller size of breastfed infants may lead to erroneous interpretations of growth faltering, followed by premature introduction of supplemental foods. This practice can be deleterious and have significant ill effects on children living in areas where sanitation is poor. However, it is equally important to acknowledge that curves that fit poorly with a population may also lead to errors, such as regarding head growth, FTT or the need for specialist services. These errors can raise barriers to correct diagnosis when a problem exists, create unnecessary stress when one does not and increase strain on overtaxed healthcare systems. Many countries will be able to use their own curves. However, because of the lack of data on unconstrained growth in sub-Saharan Africans, growth references for this population may be beneficial. Creating them for East and West African groups could be advantageous.

Analyses of secular changes have found that average height increases incrementally over generations, ${ }^{124-134}$ even in affluent populations. Continued incremental increases in height continue to be documented in countries such as Denmark, Sweden and the Netherlands (albeit at reduced rates ${ }^{16} 18135$ ), where socioeconomic constraints on growth have been effectively absent for decades.

Incremental increases appear to be due to physiological constraints, ${ }^{136}$ and are affected by maternal 

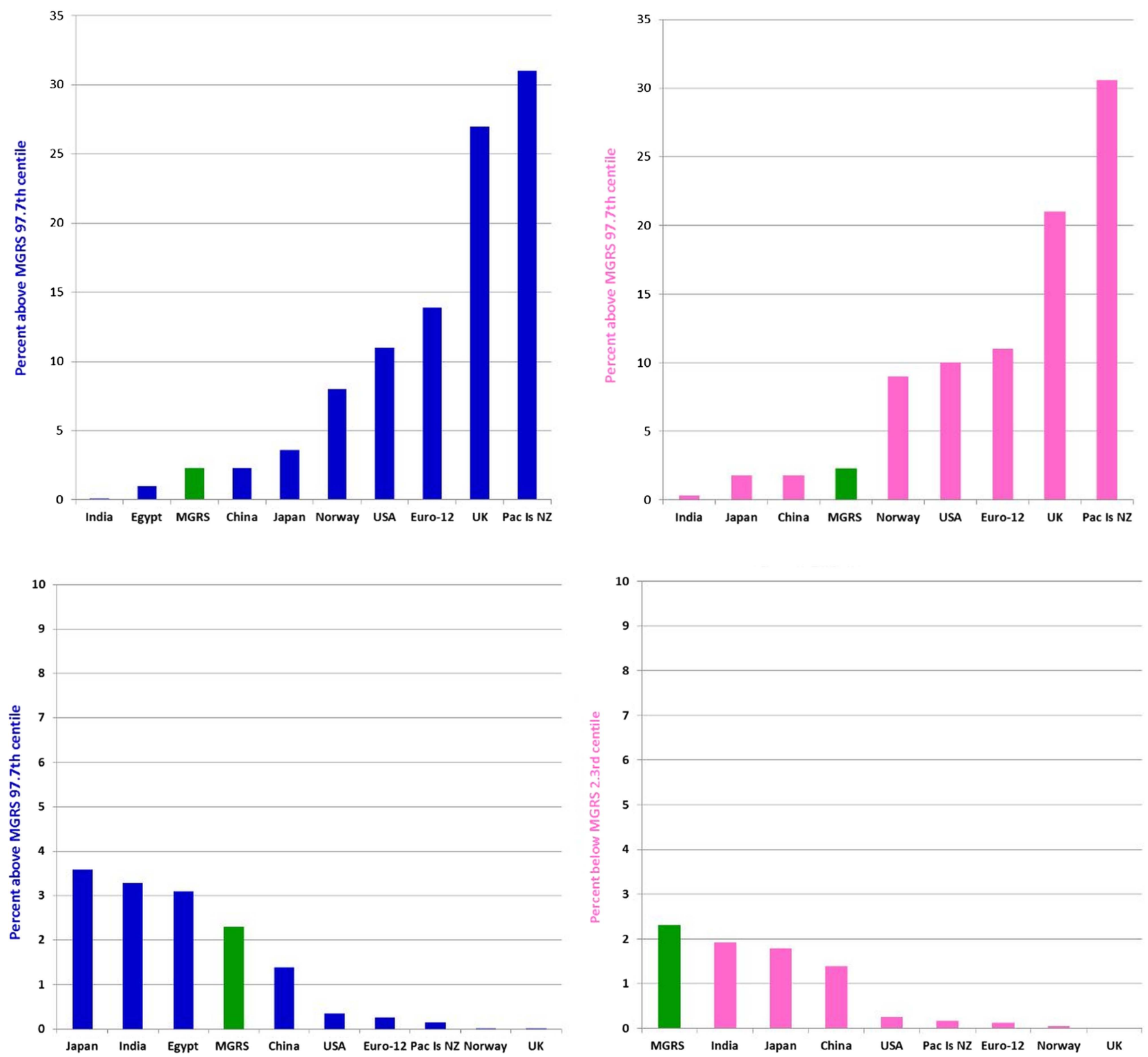

Figure 5 Estimated percentages of extreme outliers (head circumference) at age 24 months. (A) Percentage of boys (blue) or girls (pink) estimated to be above the 97.7th centile on the Multicentre Growth Reference Study (MGRS) curves. (B) Percentage of boys (blue) or girls (pink) estimated to be below the 2.3rd centile on the MGRS curves.

growth (fetal and postnatal ${ }^{137}$ ) and mid-parental height (reviewed in ref. ${ }^{138}$ ), among other factors. However, secular increases in stature have slowed considerably in some countries, yet will likely continue robustly in others for decades. ${ }^{136}$ These observations imply that a population may eventually reach a maximum mean height. Clearly, however, maximum height cannot have been reached for the vast majority of the world's populations.

On the basis of this information, the advantaged children in the WHO's study may not have represented their population's maximal sizes, unless they had come from families that had been living in optimal conditions for many generations. The MGRS did not consider this factor. While Norway may have reached or be close to a growth plateau, the five other countries in the MGRS study likely have not, and all are likely in different stages of secular change. As a consequence, although the WHO notes that its curves were designed to show how children 'should grow rather than how they grew in a particular time and place', ${ }^{6} 139$ they may describe how advantaged children in countries at different stages of secular change were growing at a certain time.

\section{Strengths and limitations}

A major strength of this study is that it is the first large-scale comparison of growth data with the MGRS data. In choosing which data to include, we were careful to select recent studies of children living in advantaged conditions. This careful selection process increased the comparability of the means reported here with the MGRS means by maximising the similarity of conditions under which the data for comparison was gathered. We 
have also compared mean head size in cohorts of breastfed children with the MGRS means wherever possible.

We attempted to reduce the risk of bias by including large studies, searching multiple sources in multiple languages and using high-quality studies. By focusing on healthy, affluent populations, we also reduced the risk of reporting on growth that had been affected by disease or poverty.

Limitations of this study include the relative lack of data from South America and Africa. Unfortunately, the majority of South American studies pooled data for both sexes, and could not be used. In addition, the dearth of studies from sub-Saharan African nations was a limitation. Although our searches were extensive, it is also possible that we may have missed publications relevant to this analysis.

Acknowledgements The authors would like to thank Martin O'Connor and Shannon Rice Long for advice and critical reading of the manuscript and $\mathrm{Dr}$ Charles McCulloch (UCSF) for statistics-related advice and critical reading. The authors are also grateful to the following for provision of data: Professor Kailash Agarwal (Health Care and Research Association for Adolescents, Noida), Dr Oskar Jenni (University Children's Hospital, Zurich), Dr Hemasree Kandraju (Nizam's College, Hyderabad, India), Dr Luciano Molinari (University Children's Hospital, Zurich), Dr Elaine Rush and Steve Taylor of Auckland University of Technology, and Professor Stef van Burren (The Netherlands Organisation for Applied Scientific Research TNO, the Netherlands).

Contributors VN conceived and designed the study. VN and AR performed the literature search and performed data analysis. VN drafted the initial report and both coauthors revised it and approved the final version. The researchers were independent from the funders.

Funding This work was funded by the Harry L Willett Foundation.

Competing interests VN and AR have support from the Harry L. Willett Foundation for the submitted work.

Provenance and peer review Not commissioned; externally peer reviewed.

Data sharing statement Both authors had full access to all of the data (including statistical reports and tables) in the study and can take responsibility for the integrity of the data and the accuracy of the data analysis.

Open Access This is an Open Access article distributed in accordance with the Creative Commons Attribution Non Commercial (CC BY-NC 3.0) license, which permits others to distribute, remix, adapt, build upon this work noncommercially, and license their derivative works on different terms, provided the original work is properly cited and the use is non-commercial. See: http:// creativecommons.org/licenses/by-nc/3.0/

\section{REFERENCES}

1. World Health Organization. WHO child growth standards: length/ height-for-age, weight-for-age, weight-for-length, weight-for-height and body mass index-for-age: methods and development. Geneva: World Health Organization, 2006:312

2. WHO Multicentre Growth Reference Study Group. Assessment of differences in linear growth among populations in the WHO Multicentre Growth Reference Study. Acta Paediatr Suppl 2006;450:56-65.

3. World Health Organization. WHO child growth standards: head circumference-for-age, arm circumference-for-age, triceps skinfold-for-age and subscapular skinfold-for-age: methods and development. Geneva: World Health Organization, 2007.

4. de Onis M, Yip R. The WHO growth chart: historical considerations and current scientific issues. Bibl Nutr Dieta 1996;(53):74-89.

5. WHO Working Group on Infant Growth. An evaluation of infant growth: the use and interpretation of anthropometry in infants. Bull World Health Organ 1995;73:165-74.
6. de Onis M, Garza C, Victora CG, et al. The WHO Multicentre Growth Reference Study: planning, study design, and methodology. Food Nutr Bull 2004;25(1 Suppl):S15-26.

7. World Health Assembly. Resolution WHA47.5. Infant and young child nutrition. Geneva: World Health Organization, 1994.

8. de Onis M, Garza C, Habicht JP. Time for a new growth reference. Pediatrics 1997;100:E8.

9. Grummer-Strawn LM, Reinold C, Krebs NF. Use of World Health Organization and CDC growth charts for children aged 0-59 months in the United States. MMWR Morb Mortal Wkly Rep 2010;55:1-15.

10. Willows ND, Sanou D, Bell RC. Assessment of Canadian Cree infants' birth size using the WHO Child Growth Standards. Am J Hum Biol 2011;23:126-31.

11. Gokcay G, Furman A, Neyzi O. Updated growth curves for Turkish children aged 15 days to 60 months. Child Care Health Dev 2008:34:454-63.

12. Juliusson PB, Roelants M, Hoppenbrouwers K, et al. Growth of Belgian and Norwegian children compared to the WHO growth standards: prevalence below -2 and above +2 SD and the effect of breastfeeding. Arch Dis Child 2011;96:916-21.

13. Schienkiewitz A, Schaffrath Rosario A, Dortschy R, et al. German head circumference references for infants, children and adolescents in comparison with currently used national and international references. Acta Paediatr 2011;100:e28-33.

14. Anzo M, Takahashi T, Sato S, et al. The cross-sectional head circumference growth curves for Japanese from birth to 18 years of age: the 1990 and 1992-1994 national survey data. Ann Hum Biol 2002;29:373-88

15. Daymont C, Hwang WT, Feudtner C, et al. Head-circumference distribution in a large primary care network differs from $\mathrm{CDC}$ and WHO curves. Pediatrics 2010;126:e836-42.

16. Tinggaard J, Aksglaede L, Sorensen K, et al. The 2014 Danish references from birth to 20 years for height, weight and body mass index. Acta Paediatrica. Epub ahead of print. doi: 10.1111/ apa.12468

17. Werner B, Bodin L. Head circumference from birth to age 48 months for infants in Sweden. Acta Paediatr 2006;95 $1601-7$

18. Fredriks AM, van Buuren S, Burgmeijer RJ, et al. Continuing positive secular growth change in the Netherlands 1955-1997. Pediatri Res 2000;47:316-23.

19. Zaki ME, Hassan NE, El-Masry SA. Head circumference reference data for Egyptian children and adolescents. East Mediterr Health Journal 2008;14:69-81.

20. Agarwal DK, Agarwal KN. Physical growth in Indian affluent children (birth-6 years). Indian Pediatr 1994;31:377-413.

21. Neyzi O, Gunöz A, Furman A, et al. Türk çocuklarında vücut ağırlığı, boy uzunluğu, baş çevresi ve vücut kitle indeksi referans değerleri. Çocuk Sağlığı Hastalıkları Derg 2008;51:1-14.

22. Copil A, Yeste $D$, Maciá J, et al. Patrones antropométricos de los recién nacidos a término de grupos étnicos de raza no caucásica procedentes de África subsahariana, Marruecos y Sudamérica nacidos en Cataluña. Ann Pediatr (Barc) 2006;65:454-60.

23. Braegger $\mathrm{C}$, Jenni $\mathrm{O}$, Konrad D, et al. Neue Wachstumskurven für die Schweiz. Schweizerische Ärztezeitung 2011;92:229-31.

24. Dawodu A, Bener A, Koutouby GA, et al. Size at birth in a rapidly developing economy: intrauterine growth pattern of UAE infants. Ann Hum Biol 2008;35:615-23.

25. El Mouzan M, Al Salloum A, Al Herbish A, et al. Health profile of Saudi children and adolescents. Riyadh: King Abdulaziz City for Science and Technology, 2008:96.

26. Patwari AK, Kulkarni R, Aneja S, et al. Anthropometric standards of privileged neonates in Maiduguri, Nigeria. Cent Afr J Med 1988;34:78-84.

27. van Buuren S. Effects of selective dropout on infant growth standards. Nestle nutrition workshop series. Paediatr Program 2010;65:167-75; discussion 75-9.

28. Beeby PJ, Bhutap T, Taylor LK. New South Wales population-based birthweight percentile charts. $J$ Paediatr Child Health 1996;32:512-18.

29. Guihard-Costa AM, Grange G, Larroche JC, et al. Sexual differences in anthropometric measurements in French newborns. Biol Neonate 1997;72:156-64.

30. Fok TF, So HK, Wong E, et al. Updated gestational age specific birth weight, crown-heel length, and head circumference of Chinese newborns. Archives of disease in childhood. Fetal Neonatal Ed 2003;88:F229-36.

31. Bertino E, Spada E, Occhi L, et al. Neonatal anthropometric charts: the Italian neonatal study compared with other European studies. J Pediatr Gastroenterol Nutr 2010;51:353-61. 
32. Olsen IE, Groveman SA, Lawson ML, et al. New intrauterine growth curves based on United States data. Pediatrics 2010;125:e214-24.

33. Kandraju H, Agrawal S, Geetha K, et al. Gestational age-specific centile charts for anthropometry at birth for South Indian infants. Indian Pediatr 2012;49:199-202.

34. Davidson S, Sokolover N, Erlich A, et al. New and improved Israeli reference of birth weight, birth length, and head circumference by gestational age: a hospital-based study. Israel Med Assoc J 2008;10:130-4.

35. Boo NY, Lye MS, Ong LC. Intrauterine growth of liveborn Malaysian infants between gestation of 28 to 42 weeks. Singapore Med $J$ 1994;35:163-6.

36. Yunis KA, Khawaja $\mathrm{M}$, Beydoun $\mathrm{H}$, et al. Intrauterine growth standards in a developing country: a study of singleton livebirths at 28-42 weeks' gestation. Paediatr Perinatal Epidemiol 2007;21:387-96.

37. Sankilampi U, Hannila ML, Saari A, et al. New population-based references for birth weight, length, and head circumference in singletons and twins from 23 to 43 gestation weeks. Ann Med 2013;45:446-54.

38. Kumar VS, Jeyaseelan L, Sebastian T, et al. New birth weight reference standards customised to birth order and sex of babies from South India. BMC Pregnancy Childbirth 2013;13:38.

39. Uehara R, Miura F, Itabashi K, et al. Distribution of birth weight for gestational age in Japanese infants delivered by cesarean section. J Epidemiol 2011;21:217-22.

40. Kheng GS. Birthweight percentile by gestational age and maternal factors that affect birthweight in Singapore. National University of Singapore, 2011.

41. Segre CAM, Colletto GMDD, Bertagnon JRD. Curvas de crescimento intra-uterino de uma população de alto nível socioeconômico. J Pediatr 2001;77:169-74.

42. Hsieh WS, Wu HC, Jeng SF, et al. Nationwide singleton birth weight percentiles by gestational age in Taiwan, 1998-2002. Acta Paediatr Taiwanica 2006;47:25-33.

43. Alshimmiri MM, Hammoud MS, Al-Saleh EA, et al. Ethnic variations in birthweight percentiles in Kuwait. Paediatr Perinatal Epidemiol 2003:17:355-62.

44. Urquia ML, Alazraqui M, Spinelli HG, et al. [Reference birthweights for the Argentine population by multiplicity of birth, sex, and gestational age]. Rev Panam Salud Publica 2011;29:108-19.

45. Rios JM, Tufino-Olivares E, Reza-Lopez S, et al. Birthweight percentiles by gestational age and gender for children in the North of Mexico. Paediatr Perinatal Epidemiol 2008:22:188-94.

46. Cunha MMA, Carreiro H, Machado MdC. Percentis do peso de nascimento para a idade gestacional, numa população de recém-nascidos. Acta Pediátr Port 2007;38:187-93.

47. Bonellie S, Chalmers J, Gray R, et al. Centile charts for birthweight for gestational age for Scottish singleton births. BMC Pregnancy Childbirth 2008;8:5

48. Kramer MS, Platt RW, Wen SW, et al. A new and improved population-based Canadian reference for birth weight for gestational age. Pediatrics 2001;108:E35.

49. Roberts $C L$, Lancaster PA. Australian national birthweight percentiles by gestational age. Med J Aust 1999;170:114-18.

50. Voigt M, Fusch C, Olbertz D, et al. Kurzmitteilung zu den Perzentilwerten für die Körpermaße der Neugeborenen. Geburtsh Frauenheilk 2006:66:956-70.

51. Skjaerven R, Gjessing HK, Bakketeig LS. Birthweight by gestational age in Norway. Acta Obstetr Gynecol Scand 2000;79:440-9.

52. Michaelsen KF, Petersen S, Greisen G, et al. Weight, length, head circumference, and growth velocity in a longitudinal study of Danish infants. Dan Med Bull 1994;41:577-85.

53. Atladottir $\mathrm{H}$, Thorsdottir I. Energy intake and growth of infants in Iceland-a population with high frequency of breast-feeding and high birth weight. Eur J Clin Nutr 2000;54:695-701.

54. Cole TJ, Williams AF, Wright CM, et al. Revised birth centiles for weight, length and head circumference in the UK-WHO growth charts. Ann Hum Biol 2011;38:7-11.

55. Nickavar A, Golnara P, Seddigh N. Determination of birth indices in healthy neonates. Acta Medica Iranica 2007;45:469-72.

56. Tanaka $\mathrm{H}$, Ishii $\mathrm{H}$, Yamada $\mathrm{T}$, et al. Growth of Japanese breastfed infants compared to national references and World Health Organization growth standards. Acta Paediatr 2013;102:739-43.

57. Patsourou A, Konstantinides T, Mantadakis E, et al. Growth of exclusively breastfed and self-weaned children of Greece aged 036 months. Breastfeed Med 2012;7:521-5.

58. Rush $\mathrm{E}$, Gao W, Funaki-Tahifote $\mathrm{M}$, et al. Birth weight and growth trajectory to six years in Pacific children. Int $J$ Pediatr Obes 2010;5:192-9.
59. Roelants M, Hauspie R, Hoppenbrouwers K. References for growth and pubertal development from birth to 21 years in Flanders, Belgium. Ann Hum Biol 2009;36:680-94.

60. Albertsson-Wikland K, Luo ZC, Niklasson A, et al. Swedish population-based longitudinal reference values from birth to 18 years of age for height, weight and head circumference. Acta Paediatr 2002;91:739-54.

61. Niklasson A, Albertsson-Wikland K. Continuous growth reference from 24th week of gestation to 24 months by gender. BMC Pediatr 2008;8:8.

62. Haschke F, van't Hof MA. Euro-growth references for length, weight, and body circumferences. Euro-Growth Study Group. J Pediatr Gastroenterol Nutr 2000;31(Suppl 1):S14-38.

63. Sreeramareddy CT, Chuni N, Patil R, et al. Anthropometric surrogates to identify low birth weight Nepalese newborns: a hospital-based study. BMC Pediatr 2008;8:16.

64. Karvonen M, Hannila ML, Saari A, et al. New Finnish reference for head circumference from birth to 7 years. Ann Med 2012;44:369-74.

65. Zong XN, $\mathrm{Li} \mathrm{H}$. Construction of a new growth references for China based on urban Chinese children: comparison with the WHO growth standards. PLOS ONE 2013;8:e59569.

66. Nielsen AM, Olsen EM, Juul A. New Danish reference values for height, weight and body mass index of children aged $0-5$ years. Acta Paediatr 2010;99:268-78.

67. Juliusson PB, Roelants M, Eide GE, et al. [Growth references for Norwegian children]. Tidsskr Nor laegeforen 2009;129:281-6.

68. Wright CM, Inskip HM, Godfrey K, et al. Monitoring head size and growth using the new UK-WHO growth standard. Arch Dis Child 2011;96:386-8.

69. Loke KY, Lin JB, Mabel DY. 3rd College of paediatrics and child health lecture-the past, the present and the shape of things to come. Ann Acad Med Singapore 2008:37:429-34.

70. Centers for Disease Control and Prevention for the Academy of Pediatrics. 2007 Children and adolescents standard growth charts (South Korea). Seoul, 2007.

71. Hui LI. Growth standardized values and curves based on weight, length/height and head circumference for Chinese children under 7 years of age. Chin J Pediatr 2009;47:173-8.

72. Mazurin AB, Bortontssov IM. Пропедевтика детских болезней (Introduction to childhood illnesses). 2nd edn. Moscow: Meditsina, 2000

73. Vignerová J, Riedlová J, Blaha P, et al. 6th National Anthropological Research on Children and Youth 2001 (Celostátní Antropologicky Výzkum Dití a Mláde e 2001). Prague: Charles University in Prague (Univerzita Karlova v Praz), 2006.

74. Moon JS. Secular trends of body sizes in Korean children and adolescents: from 1965 to 2010. Korean J Pediatr 2011; 54:436-42.

75. Webster V, Denney-Wilson E, Knight J, et al. Describing the growth and rapid weight gain of urban Australian Aboriginal infants. $J$ Paediatr Child Health 2013;49:303-8.

76. Centre FN. First Nations Regional Longitudinal Health Survey (RHCS) 2002/03. Ottawa: First Nations Centre, 2005:312.

77. Lavallee C. Anthropometric measurements and growth charts for Cree children of James Bay, from 0 to 5 years old. Arctic Med Res 1988;47(Suppl 1):204-8.

78. Remontet L, Mamelle N, Locard E, et al. [Growth curves from birth to 6 years of age: growth in weight, height and cranial circumference according to sex]. Arch Pediatr 1999;6:520-9.

79. Gesundheitsberichterstattung des Bundes. Referenzperzentile für anthropometrische Maßzahlen und Blutdruck aus der Studie zur Gesundheit von Kindern und Jugendlichen in Deutschland (KiGGS) 2003-2006. Berlin: Robert Koch-Institut, 2011.

80. Greece MoHo. Secondary. 2012. http://www.moh.gov.gr/articles/ citizen/anakoinwseis-ndash-egkyklioi/173-bibliario-ygeias-paidioy

81. Olafsdottir AS, Magnusardottir AR, Thorgeirsdottir $\mathrm{H}$, et al. Relationship between dietary intake of cod liver oil in early pregnancy and birthweight. BJOG 2005;112:424-9.

82. Marwaha RK, Tandon N, Ganie MA, et al. Nationwide reference data for height, weight and body mass index of Indian schoolchildren. Natl Med J India 2011;24:269-77.

83. Agarwal DK, Agarwal KN, Upadhyay SK, et al. Physical and sexual growth pattern of affluent Indian children from 5 to 18 years of age. Indian Pediatr 1992;29:1203-82.

84. Hoey HM, Cox LA. Head circumference standards for Irish children Acta Paediatr Scand 1990;79:162-7.

85. Cacciari E, Milani S, Balsamo A, et al. Italian cross-sectional growth charts for height, weight and BMI (2 to $20 \mathrm{yr}$ ). J Endocrinol Invest 2006;29:581-93.

86. Bordom JH, Billot L, Gueguen R, et al. New growth charts for Libyan preschool children. East Mediterr Health $J$ 2008;14:1400-12. 
87. Fredriks AM, van Buuren S, Jeurissen SE, et al. Height, weight body mass index and pubertal development references for children of Moroccan origin in the Netherlands. Acta Paediatr 2004:93:817-24.

88. van Buuren S, Fredriks M. Worm plot: a simple diagnostic device for modelling growth reference curves. Stat Med 2001;20: 1259-77.

89. Hof $M H$, van Dijk AE, van Eijsden M, et al. Comparison of growth between native and immigrant infants between $0-3$ years from the Dutch ABCD cohort. Ann Hum Biol 2011;38:544-55.

90. Fredriks AM, van Buuren S, Jeurissen SE, et al. Height, weight, body mass index and pubertal development reference values for children of Turkish origin in the Netherlands. Eur J Pediatr 2003;162:788-93.

91. McCowan L, Stewart AW. Term birthweight centiles for babies from New Zealand's main ethnic groups. Aust N Z J Obstetr Gynaecol 2004;44:432-5.

92. Rush E, Obolonkin V, Savila F. Growth centiles of Pacific children living in Auckland, New Zealand. Ann Hum Biol 2013;40:406-12.

93. Rush EC, Paterson J, Obolonkin VV, et al. Application of the 2006 WHO growth standard from birth to 4 years to Pacific Island children. Int J Obes 2008:32:567-72.

94. Palczewska I, Niedzwiecka Z. Siatki centylowe do oceny rozwuju somatycznego dzieci i mlodzieży (Centile charts to assess the somatic development of children and youth). Warsaw, 1999.

95. Kulaga Z, Grajda A, Gurzkowska B, et al. Polish 2012 growth references for preschool children. Eur J Pediatr 2013;172:753-61.

96. Sobradillo BAA, Aresti U, Bilbao A, et al. Curvas y tablas de crecimiento. Fundación Faustino Orbegozo Eizaguirre, 2007.

97. Centers for Disease Control and Prevention. 2000 CDC growth charts for the United States. Hyattsville, MD: Public Health Service, CDC, National Center for Health Statistics, 2002.

98. Saari A, Sankilampi U, Hannila ML, et al. New Finnish growth references for children and adolescents aged 0 to 20 years: length/ height-for-age, weight-for-length/height, and body mass index-for-age. Ann Med 2011;43:235-48.

99. Rush EC, Freitas I, Plank LD. Body size, body composition and fat distribution: comparative analysis of European, Maori, Pacific Island and Asian Indian adults. Br J Nutr 2009;102:632-41.

100. Fennoy I. Effect of obesity on linear growth. Curr Opin Endocrinol Diabetes Obes 2013:20:44-9.

101. Rosario AS, Schienkiewitz A, Neuhauser H. German height references for children aged 0 to under 18 years compared to WHO and CDC growth charts. Ann Hum Biol 2011:38:121-30.

102. Dewey KG, Heinig MJ, Nommsen LA, et al. Growth of breast-fed and formula-fed infants from 0 to 18 months: the DARLING Study. Pediatrics 1992;89(6 Pt 1):1035-41.

103. Hui LL, Schooling CM, Cowling BJ, et al. Are universal standards for optimal infant growth appropriate? Evidence from a Hong Kong Chinese birth cohort. Arch Dis Child 2008;93:561-5.

104. Aarts C, Kylberg E, Hofvander Y, et al. Growth under privileged conditions of healthy Swedish infants exclusively breastfed from birth to 4-6 months: a longitudinal prospective study based on daily records of feeding. Acta Paediatr 2003;92:145-51.

105. Haschke F, van't Hof MA. Euro-growth references for breast-fed boys and girls: influence of breast-feeding and solids on growth until 36 months of age. Euro-Growth Study Group. J Pediatr Gastroenterol Nutr 2000;31(Suppl 1):S60-71.

106. Wright $\mathrm{C}$, Lakshman $\mathrm{R}$, Emmett $\mathrm{P}$, et al. Implications of adopting the WHO 2006 Child Growth Standard in the UK: two prospective cohort studies. Arch Dis Child 2008;93:566-9.

107. Roelants M, Hauspie R, Hoppenbrouwers K. Breastfeeding, growth and growth standards: performance of the WHO growth standards for monitoring growth of Belgian children. Ann Hum Biol 2010;37:2-9.

108. Nold JL, Georgieff MK. Infants of diabetic mothers. Pediatr Clin North Am 2004;51:619-37, viii.

109. Moffatt MEK, Kato C, Watters GV. Length, weight, and head circumference in Quebec Cree children circulation health University of Washington Press, 1985:170-72.

110. Partington MW, Roberts N. The heights and weights of Indian and Eskimo school children on James Bay and Hudson Bay. Can Med Assoc J 1969;100:502-9.

111. de Onis M, Onyango AW, Van den Broeck J, et al. Measurement and standardization protocols for anthropometry used in the construction of a new international growth reference. Food Nutr Bull 2004;25(1 Suppl):S27-36.

112. van't Hof MA, Haschke F. The Euro-Growth Study: why, who, and how. J Pediatr Gastroenterol Nutr 2000;31(Suppl 1):S3-13.
113. Donma MM, Donma O. The influence of feeding patterns on head circumference among Turkish infants during the first 6 months of life. Brain Dev 1997;19:393-7.

114. World Health Organization. Growth patterns of breastfed infants in seven countries. WHO Working Group on the Growth Reference Protocol and WHO Task Force on Methods for the Natural Regulation of Fertility. Acta Paediatr 2000;89:215-22.

115. Mohamed AJ, Onyango AW, de Onis M, et al. Socioeconomic predictors of unconstrained child growth in Muscat, Oman. East Mediterr Health J 2004;10:295-302.

116. Owusu WB, Lartey A, de Onis M, et al. Factors associated with unconstrained growth among affluent Ghanaian children. Acta Paediatr 2004;93:1115-19.

117. Bhandari N, Bahl R, Taneja S, et al. Growth performance of affluent Indian children is similar to that in developed countries. Bull World Health Organ 2002;80:189-95.

118. WHO Multicentre Growth Reference Study Group. Enrolment and baseline characteristics in the WHO Multicentre Growth Reference Study. Acta Paediatr Suppl 2006;450:7-15.

119. Meredith HV. Human head circumference from birth to early adulthood: racial, regional, and sex comparisons. Growth 1971;35:233-51.

120. Houghton P. People of the great ocean: aspects of human biology of the early Pacific. Cambridge; New York, NY: Cambridge University Press, 1996.

121. Ball R, Shu C, Xi P, et al. A comparison between Chinese and Caucasian head shapes. Appl Ergon 2010;41:832-9.

122. Howells WW. Skull shapes and the map: craniometric analyses in the dispersion of modern Homo. Cambridge, MA: Peabody Museum of Archaeology and Ethnology Distributed by Harvard University, 1989

123. Howells WW. Who's who in skulls: ethnic identification of crania from measurements. Cambridge, MA: Peabody Museum of Archaeology and Ethnology, Harvard University, 1995.

124. van Wieringen JC. Secular growth changes. In: Falkner F. ed. Human growth: a comprehensive treatise. New York: Plenum Press, 1986:307-31.

125. Takaishi M. Growth standards for Japanese children-an overview with special reference to secular change in growth. In: Hauspie RLGFalkner F. eds. Essays on auxology presented to James Mourilyan Tanner by former colleagues and fellows. Welwyn Garden City: Castlemead Publications, 1995:302-11.

126. Sanna E, Floris G, Cosseddu GG. Secular trend in height in Sardinian conscripts drafted from 1879-1883 to 1983-1986. Anthropol Anz 1993;51:225-32.

127. Staub K, Ruhli F, Woitek U, et al. The average height of 18- and 19-year-old conscripts $(\mathrm{N}=458,322)$ in Switzerland from 1992 to 2009 , and the secular height trend since 1878. Swiss Med Wkly 2011;:141:w13238.

128. Franca Junior I, da Silva GR, Monteiro CA. [Secular trends of height in adulthood of children born in the city of Sao Paulo, Brazil from 1950-1976]. Rev Saude Publica 2000;34(6 Suppl):102-7.

129. Vargas DM, Arena LF, Soncini AS. [Secular trends in stature growth in Blumenau-Brazil in relation to human development index (HDI)]. Rev Assoc Med Bras 2010;56:304-8.

130. Jaeger U, Zellner K, Kromeyer-Hauschild K, et al. [Body height, body weight and body mass index of German military recruits. Historical retrospect and current status]. Anthropol Anz 2001:59:251-73

131. Bodzsar EB, Zsakai A. Some aspects of secular changes in Hungary over the twentieth century. Coll Antropol 2002;26:477-84.

132. Marques-Vidal P, Madeleine G, Romain S, et al. Secular trends in height and weight among children and adolescents of the Seychelles, 1956-2006. BMC Public Health 2008;8:166.

133. Malina RM. Secular trends in growth, maturation and physical performance: a review. Anthropol Rev 2004;67:3-31.

134. Bushby KM, Cole T, Matthews JN, et al. Centiles for adult head circumference. Arch Dis Child 1992;67:1286-7.

135. Lissner L, Mehlig K, Sjoberg A, et al. Secular trends in weight height and BMI in young Swedes: the 'Grow up Gothenburg' studies. Acta Paediatr 2013;102:314-17.

136. Cole TJ. The secular trend in human physical growth: a biological view. Econ Hum Biol 2003;1:161-8.

137. Hennessy E, Alberman E. Intergenerational influences affecting birth outcome. I. Birthweight for gestational age in the children of the 1958 British birth cohort. Paediatr Perinat Epidemiol 1998;12 (Suppl 1):45-60.

138. Cole TJ. Secular trends in growth. Proc Nutr Soc 2000;59:317-24.

139. Garza C, de Onis M. Rationale for developing a new international growth reference. Food Nutr Bull 2004;25(1 Suppl):S5-14. 